\title{
The utilisation of the performances of Neil Diamond for improving the classroom practices of educators: an educational appreciation
}

\author{
JPRETORIUS AND C VAN WYK
}

\begin{abstract}
In this research the 5D-framework of Appreciative Inquiry is used to investigate the possibility of applying the attributes and artistic strategies of the pop singer Neil Diamond for the improvement of classroom practices of educationalists. During the attendance of the performances of Diamond in 2011 in South Africa the writers and five other educationalists have identified five broad qualities and practices of Diamond. These may have application value in a school or university classroom: passionate enthusiasm, purposeful dedication, communication and interaction with the audience, refusing to conform/creating variation as well as good planning. This is the first time that the 5D-cycle has been used to study the possible utilisation of a live performance of a popular artist to facilitate the professional development of educationalists.
\end{abstract}

Key words: Appreciative Inquiry, classroom practices, educationalists, Neil Diamond, performance

\section{Introduction}

The premise that educationalists in general - and specifically teachers or lecturers - are perpetually in search of strategies to improve their classroom practices or that they should at least be, is relatively certain. Most teachers, we think and hope, would surely want to improve their teaching practices in due course. Yet, what would the potential sources of, and platforms for, the said improvement be? Probable and important platforms for improving one's classroom practices would naturally include in-service training sessions, self-reflection, discussions and collaborations with colleagues, educational journals, websites and professional associations. Our intention here is neither to deny nor to underestimate the value of such developmental tools.

At both personal and professional level - no doubt largely as a result of our own half-hearted attempts - we have seldom been able to launch substantial improvements from such platforms. We have found them to be relatively poor with regard to enlightening insights

1 Corresponding author: Jannie Pretorius $(\mathrm{PhD})$ is a lecturer of Natural and Life Sciences Education in the School of Mathematics, Natural Sciences and Technology Education at the University of the Free State, Email: PretoriusJPH@ufs.ac.za

2 Christo van Wyk is a lecturer of Physical and Natural Science Education in the School of Mathematics, Natural Sciences and Technology Education at the University of the Free State, Email: vanwykc@ufs.ac.za

TD The Journal for Transdisciplinary Research in Southern Africa, 9(3), Special edition, December 2013, pp. 493504. 
and, at times, even boring. The presenters have often been unable to hold our attention. Thus, in the present study, we wish to propose and utilise an additional platform for the improvement of the classroom practices of teachers: appreciating the arts in general and specifically, a popular music artist's live performances.

We believe, and it is indeed our experience, that pop music offers an exciting alternative platform for the improvement of classroom practices. Frith (2001:107) describes the potentially transformative effect that pop music has on people: "And if unexpected things happen to songs, so songs have unexpected effects on us". Neil Diamond, the popular artist under investigation in this study, explains it like this: "All of these songs came in the flash of some creative inspiration, and at moments that were signposts, pointing toward what the rest of my life and career might be like" ${ }^{3}$

\section{Teaching as a form of art}

However, in order to utilise the arts as platform for the professional development of teachers, we would firstly require a fundamental assumption: teaching is also an art and teachers, by implication, can also be artists. It would surely be futile to suggest that teachers can learn something from artists about teaching if there were no similarities between the arts and teaching - at least at certain levels. If we were to assume that teaching is also an art (as educationalists do indeed commonly allege) we would be able to utilise the contours and attributes (Soanes \& Stevenson, 2005:102: "a quality or feature regarded as a characteristic or inherent part of someone or something") of artistry in the life and performances of a pop artist like Neil Diamond as guidelines for the improvement of classroom practice. It is our opinion that an artist, like Diamond, and a teacher or lecturer in a South African classroom or lecture hall have to contend with the same basic challenge: to get and keep the attention of their respective audiences. We argue that Diamond's very survival as a performing artist relies on his ability to keep his audiences engaged. Because he has succeeded in doing just this over many years we believe that teachers and lecturers alike might learn a lot about improving their classroom practices from studying his performances.

References to teaching as a form of art were indeed found: according to Feldman and McPhee (2008:126-128) teaching is as much an art as it is a science. We consider the following definition of art as advanced by Soanes and Stevenson (2005:88) to be a sound base for further arguments for the purposes of the present study: "A skill at doing a specific thing, typically one acquired through practice: the art of conversation." Bloch (2009:104) furthermore considers teaching to be "... a difficult and complex, multifaceted and multilayered art and science”.

Based on the above, we deem that it is reasonable to consider teaching to be an art. We can start to investigate what educationalists might learn from artists about their classroom practice. We have used the process of Appreciative Inquiry to conduct our research. We shall now discuss our appreciative methodology accordingly.

3 Quotation from booklet included in Neil Diamond - The Greatest Hits 1966-1992 CD. 


\section{Goals of the study: The Definition Phase of Appreciative Inquiry}

Pretorius (2009) utilised the process of Appreciative Inquiry during a workshop with teachers aimed at investigating pop star Cliff Richard's artistry with a view to investigating the positive core of Richard's artistry. In Pretorius's study, Richard's attributes were used as a proposed framework for teachers' professional development. Pretorius, du Toit, Martin and Daries (2013) similarly used the artistry of the pop group ABBA to facilitate learning by student teachers. In the present case, we have also decided to conduct an Appreciative Inquiry into the artistry of Neil Diamond.

Cooperrider, Whitney and Stavros (2008:3) describe Appreciative Inquiry (hereafter called AI) as follows:

Appreciative Inquiry is the cooperative co-evolutionary search for the best in people, their organizations, and the world around them. It involves the discovery of what gives 'ife' to the living system when it is most effective, alive, and constructively capable in economic, ecological, and human terms. AI involves the art and practice of asking questions that strengthen a system's capacity to apprehend, anticipate, and heighten positive potential.

Whitney and Trosten-Bloom (2010:1-2) give the following description of AI:

Appreciative Inquiry is the study of what gives life to human systems when they function at their best. This approach to personal change and organization change is based on the assumption that questions and dialogue about strengths, successes, values, hopes, and dreams are themselves transformational. In short, Appreciative Inquiry suggests that human organizing and change at its best is a relational process of inquiry, grounded in affirmation and appreciation. The following beliefs about human nature and human organizing are the foundation of appreciative inquiry:

- People individually and collectively have unique gifts, skills, and contributions to bring to life.

- Organizations are buman social systems, sources of unlimited relational capacity, created and lived in language.

- The images we hold of the future are socially created and, once articulated, serve to guide individual and collective actions.

- Through human communication - inquiry and dialogue - people can shift their attention and action away from problem analysis to lift up worthy ideals and productive possibilities for the future.

AI is an approach to change with endless variation (Whitney \& Trosten-Bloom, 2010:13) and can thus easily be adapted and improved. Though no two appreciative inquiry processes are ever identical, they are nevertheless characterised by the 5-D cycle that we followed (see Figure 1). 


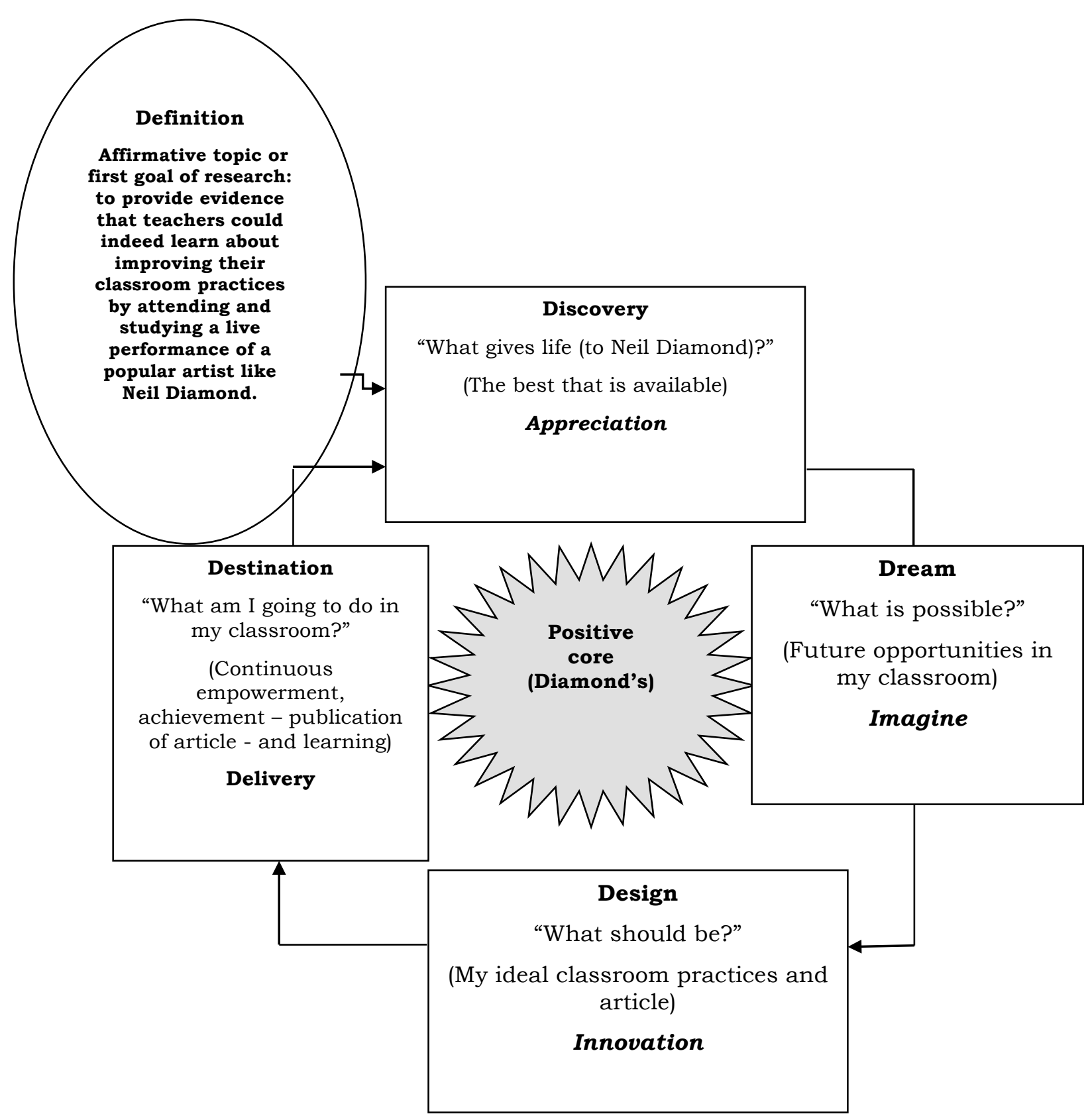

Figure 1: The appreciative inquiry 5-D cycle (Adapted from Cooperrider, Whitney \& Stavros, 2008, and Whitney \& Trosten-Bloom, 2010:6.)

According to Watkins, Moir and Kelly (2011: 36) an Appreciative Inquiry starts with a Definition phase during which the inquiry goals are developed (see Figure 1). Whitney and Trosten-Bloom (2010:7) argue that, because human systems move towards that which they are studying, the choice of topic or goal is of key importance.

The first goal of our study is to provide evidence that, after attending and studying a live performance of a successful performer like Neil Diamond, teachers and lecturers would 
indeed be able to identify attributes and strategies of the singer. These might enable them to improve their classroom practices. The second goal of our research is to validate the credibility of this learning process by embedding what might possibly be learnt into current scientific educational literature. The rationale behind this has powerful implications for the process of lifelong learning: instead of viewing it as a series of isolated events, teachers might be enabled to utilize every song, performance or work of art that they encounter as a potential source of learning about their classroom practices.

It is now necessary that we describe the rest of our research processes.

\section{Research plan, design and development}

Our next task was identifying positive themes (Whitney \& Trosten-Bloom, 2010:136) from Neil Diamond's performances and artistry to enable us to compile the Appreciative Inquiry interview protocol (Cooperrider et al., 2008:62). We wanted to use the interview protocol during the appreciative research interviews with a view to identifying educators positive experiences and insights regarding the possible classroom applications of Diamond's performances.

During the preliminary phase of our research we have therefore shown two of Diamond's performances of his song, Sweet Caroline, - in 1976 in Sydney (Diamond, 2008a), and in 2008 in New York (Diamond, 2008b) - to the staff members of two primary schools - one in Bloemfontein and the other in Welkom. The two staff groups identified five corresponding positive themes regarding Diamond's artistry that might have application value in a classroom. Three appreciative questions, dealing with the identified educational themes were subsequently developed and included in the structured interview protocol:

- What could teachers learn from Neil Diamond?

- Do you sometimes do in your classroom what Neil Diamond does? Stated differently: do you see yourself in how he does things?

- What did you learn from the performance that could contribute to your own personal professional career/development as a teacher/lecturer?

The next step in the AI process was to decide what form of involvement would be the most suitable (Whitney \& Trosten-Bloom, 2010:24). Depending on the purpose of the investigation, the availability of resources and the time frame, large numbers of people can be involved - like when an AI conference is held, core groups involving fewer people can be put together, or small AI learning teams (Whitney \& Trosten-Bloom, 2010:32) can be involved in specific projects (Whitney \& Trosten-Bloom, 2010:24).

Due to the fact that the first goal of our study was to provide evidence that teachers could indeed learn about improving their classroom practices by attending and studying a live performance of a popular artist like Neil Diamond, we chose to compose an informal AI learning team comprising of the two writers (as interviewers) and five other educators (four teachers and one lecturer). The additional team members were recruited by asking educators who had attended the performances whether they would be willing to participate in appreciative interviews. Since all the questions asked would be appreciative of nature and since only the first names of the participants would be mentioned in the research report, a non-threatening and ethically sound research environment was created. The five additional 
team members' involvement would be limited to being respondents during the appreciative interviews. We were extremely privileged to obtain their cooperation as, having attended the performances, they were able to make direct observations. Dey (1993), according to Ary, Jacobs and Sorensen (2010:497), considers direct observation to be a factor that enhances data quality. Abercrombie and Longurst (1998, in Longhurst, 2007:260) describe the characteristics of a pop concert in the following way:

The simple audience, as represented, for example, by an audience at a pop music concert, involves relatively direct communication from performers to audience; the performance takes place in a confined locale, tends to be highly ceremonial in the sense that it is a special event and the space of the performance is ritualistic, and the site has a high level of meaning for the participants. The performance and the audience response takes place in public and the performers are separated from the audience by clear boundaries. The attention level of the audience with respect to the performance is high.

It therefore presented us with a unique opportunity. The two writers and three of the other team members attended the concert in Soweto (see figure 2), while two of them attended the concert in Cape Town. Figure 3 is presented alongside Figure 2, illustrating the striking similarity between Diamond, performing his songs on stage, and a teacher, presenting a class.

The team members were all educators because we obviously wanted to identify possible classroom applications from Diamond's performances. One of the appreciative interviews with Annelie (see Table 1) was conducted telephonically. The others were conducted personally. The two writers also conducted appreciative interviews with each other, bringing the total number of interviews to seven.
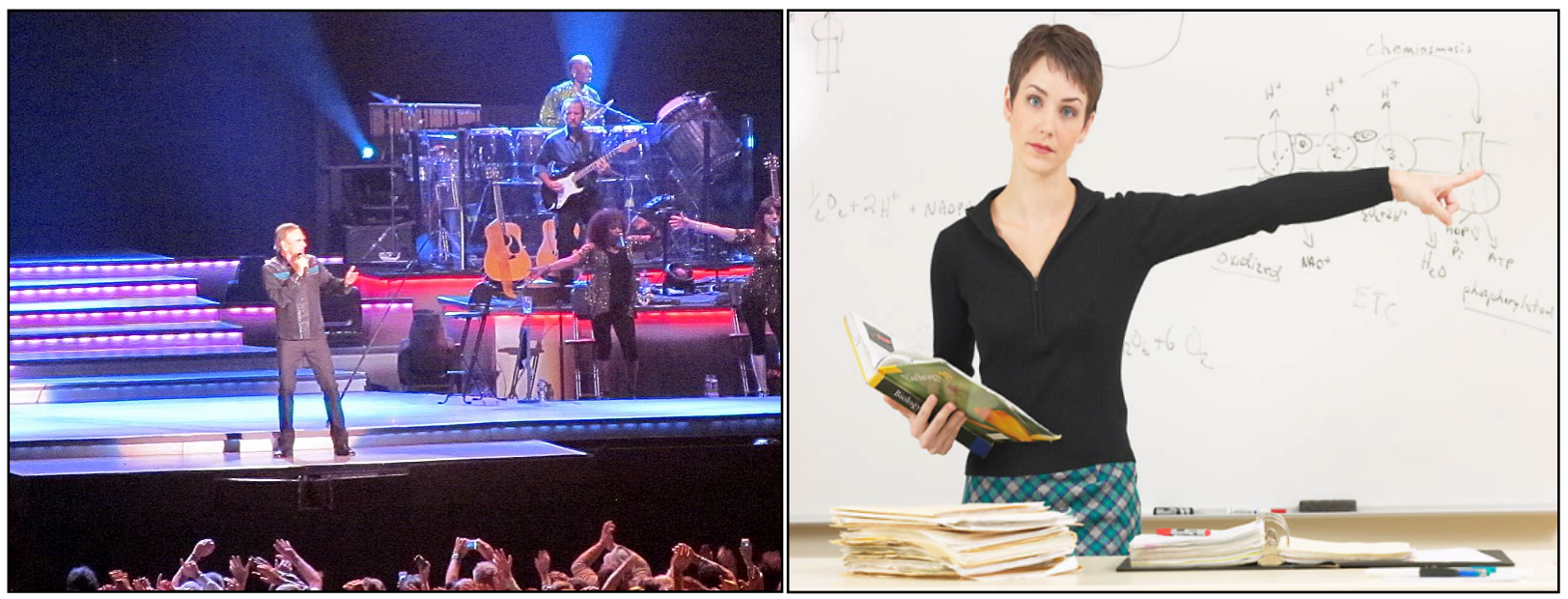

Figures 2 and 3: Diamond performing in Soccer City, Soweto and a teacher "performing" in a classroom.

The appreciative interviews are part of the second or Discovery phase of the 5-D model that we used as a research framework (see Figure 1). Whitney and Trosten-Bloom (2010:7) describe this phase as the following: "Discovery is the extensive, cooperative search to understand the 'best of what is and has been'. It is typically conducted via one-on-one interviews, though it may also include focus groups and large-group meetings." Cooperrider et al. (2008:6) provide the following description of this phase: "As part of the Discovery 
process, individuals engage in dialogue and meaning-making. This is simply the open sharing of discoveries and possibilities."

Phase three of the 5-D model is the Dream phase (Whitney \& Trosten-Bloom, 2010:8), which they describe as the following: "Dream is an energizing exploration of 'what might be'." In our investigation, this phase consisted of two questions that the team members had to answer during the appreciative interviews: "What could teachers learn from Neil Diamond?" and "What did you learn during the performance that could contribute to your own professional career/development as a teacher/lecturer?"

The fourth or Design phase of this AI entailed an analysis of the responses and the identification and discussion of positive themes that represent the essence of what teachers and other educationalists could learn from Diamond's performances. The final Destiny phase of the research process involved the submission of the manuscript for peer review and the ultimate publication thereof.

\section{Responses of team members and positive themes identified: what can teachers learn from Neil Diamond?}

In this section, we shall present and discuss the responses of the AI learning team members and analyse these to identify positive themes that could serve as direction indicators for teachers' professional development.

In response to the first question - as to what teachers could learn from Neil Diamond Jannie, who attended the performance in Soccer City, said that they should be absolutely professional and put on a perfect show in spite of difficult personal circumstances. Christo also attended the performance in Soccer City and he said that teachers should be on time, because the performance in Soweto started twenty minutes later than scheduled. Teachers might also take note of how Diamond uses his voice and also acknowledge their audience's the learners' - participation. Conrad, a member of the Soccer City audience, argued that teachers should display Diamond's dedication - how he gets things across to people. He observed that fifty-two thousand people focused on Diamond. Teachers must achieve this in their classrooms, even if there might only be thirty children attending the class.

Both Annelie, who attended the Soccer City show, and Lenie, who attended the show in Cape Town, felt that passion is the key when one wants to involve people in what you are doing. Annelie also mentioned dedication, hard work, and enjoying what one does. Elmarie, who attended the Soccer City performance, argued that teachers should also plan as thoroughly for their classes as Diamond when he writes a song: "It's not something that is simply dashed off." Suzette, who attended Diamond's performance in Cape Town, was impressed by his dedication, consistency and tidiness. She contended that Diamond is conservative, since he did not perform in South Africa during the apartheid years.

In response to the second question - "Do you sometimes do in your classroom what Neil Diamond does? Stated differently: Do you see yourself in how he does things?" Jannie articulated that he enjoys the connection that he has with students and they laugh a lot in class. Christo replied that ordinary artists have notes on the floor, but Diamond did it without notes. Christo said that he also teaches without notes. $\mathrm{He}$, too, is enthusiastic and passionate. He teaches from his own experience since he shares his life experiences with his students. According to Conrad he talks quite a lot to children in his classes; he does not only teach, but talks to them. He creates a relaxed atmosphere. 
Annelie also enjoys her audience and their interaction. She enjoys what she receives. Elmarie declared that she also believes in a variaty of teaching and learning activities. Lenie associated herself with the interaction between Diamond and his audience; provoking a reaction, she speaks to children in the classroom about what has happened. There is a sufficient amount of interaction between herself and her class. She often wears a mask and leaves her problems at home. Suzette responded in poetic terms: "Yes, we act, we become the performers."

In response to the last question: "What did you learn from the performance that could contribute to your personal professional career/development as a teacher/lecturer?" Jannie declared that he never wants to stop teaching with total commitment. Christo will strive to better the connection with the students in his class. Conrad simply enjoyed the evening, so he did not give the question any thought - nevertheless, he will try to emulate Diamond's contagious energy, to always be purposeful. Annelie stated that one has to be a master of what one does: one should prepare well for every lesson. Elmarie had a powerful one worded answer: "Humour", while Lenie was impressed by Diamond's passion and enthusiasm: “... for doing what I do, to the best of my ability, and transferring it to the children so they develop a love for my subject. Enthusiasm." Suzette felt that one should be true to yourself: "Stay relevant and do not conform.”

Five broad qualities and practices of Diamond that may have educational significance can, inter alia, be identified from team members' responses above:

- Passionate enthusiasm

- Purposeful dedication

- Communication and interaction with the audience

- Refusing to conform/creating variation and variety

- Good planning

In our discussion of the five qualities and practices, two acknowledged educational sources (Feldman and McPhee, 2008 and Killen, 2010) are utilised as sources of theoretical professional knowledge to illustrate the suitability, validity and credibility of the team members' insights for the improvement of classroom or pedagogical practice. This is to address the second goal of our research: to validate the credibility of the learning process by embedding what the learning team has learnt into current scientific educational literature.

In their discussions of the pedagogical practices of outstanding teachers, both Feldman and McPhee (2008) and Killen (2010) do indeed refer to all of the aforementioned qualities and practices as having relevance for improved classroom practice.

\subsection{Passionate enthusiasm}

Feldman and McPhee (2008:130) regard enthusiasm to be a quality possessed by good teachers who communicate and teach effectively: "They are excited about the subject they teach and present the material in an engaging manner. They challenge students at an appropriate level to keep the learning interesting."

Killen (2010:37) further reports that such teachers are passionate not only about their subjects but also about the teaching of their subjects. Enthusiasm is part of a larger group of behaviours, known as teacher affect - behaviour emanating from attitudes, values and emotions. Yet, enthusiasm is that particular form of affective behaviour mostly supported by research (Killen, 2010:37). He further justifies it as the following: 
'Enthusiastic teachers are more successful than unenthusiastic teachers at engaging learners in learning' (Killen, 2003a:77), and when learners see that their teacher is enthusiastic, this influences their motivation and their perceptions of other teacher behaviours (such as how clearly the teacher explains things, which in turn positively influences student learning (Killen, 2010:37).

\subsection{Purposeful dedication}

Feldman and McPhee (2008:347-351) identify dedication as one of the 'habits-of-mind' of good teachers: "Not giving up easily is the key to this habit" and, "Recognizing the need to act when action is called for, stepping forward in response. Persisting, patiently, as the situation may require."

Killen (2010:38) further stresses the importance of dedication as a practice common among outstanding teachers. Such teachers are dedicated not only to teaching but also to assisting their students to learn effectively. The most common among the indicators of teachers' dedication, is their loyal adherence to the norms and standards of their profession, their assistance to learners beyond the call of duty (by mentoring and coaching), their development of the philosophy and values of a school, as well as their loyalty to the profession - even when it is demanding and stressful (Killen, 2010:38). There is also considerable evidence that dedicated teachers would probably be more open to innovation and policy change than less committed teachers (Elliot \& Crosswell, 2002 in Killen, 2010:38).

\subsection{Communication and interaction with the audience}

The affection and interaction between Diamond and his audience is evident from Figure 4. In figure 5 a scene from the movie The First Grader represents the comparative feelings and interaction typical of some educational situations.
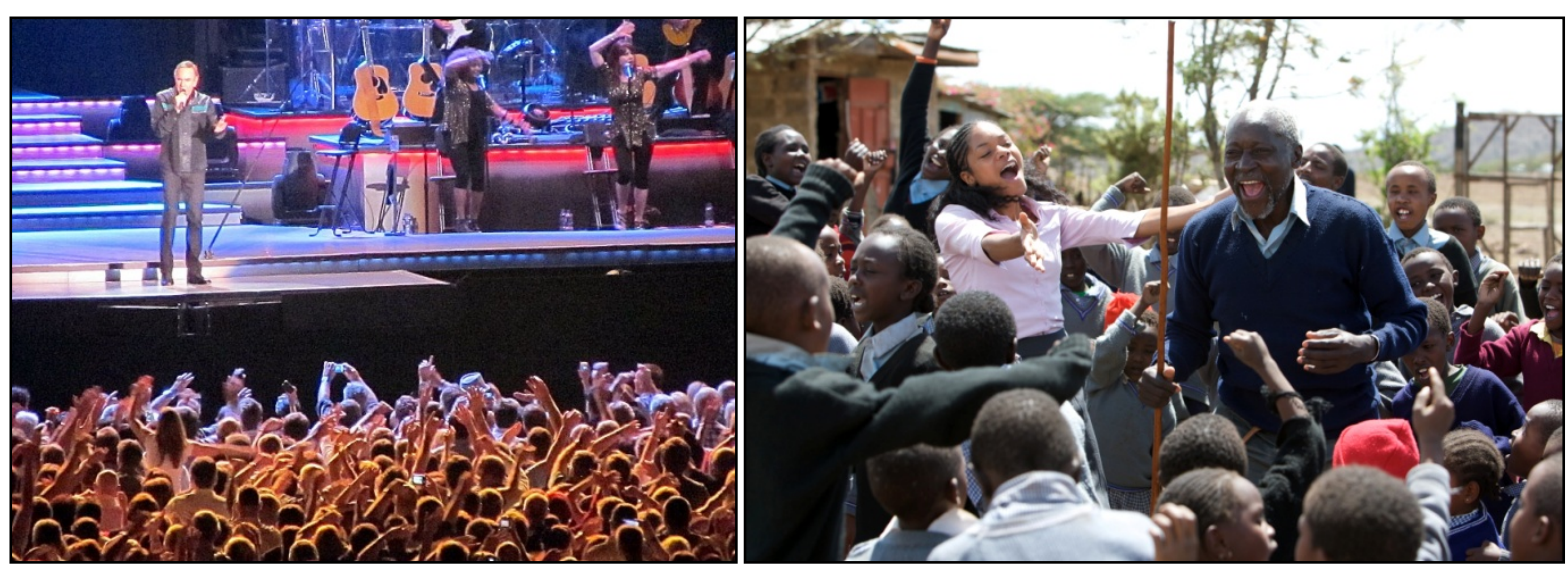

Figures 4 and 5: Diamond's affectionate interaction with the audience and Jane (Naomie Harris) celebrating with the learners and Maruge (Oliver Litondo) - a rather aged learner - in The First Grader - a BBC film.

The teacher should also treat students with respect and manage their behaviour by means of effective communication and interpersonal skills (Feldman \& McPhee, 2008:378). These include using courteous language, an inclusive attitude, listening to learners respectfully and being a role model of respect, common courtesy and understanding (Feldman \& McPhee, 2008:378). 
These authors further argue that teachers should rather converse with their learners than speak tolat them. Learners who see that their teachers are truly trying to understand their perspectives and respecting these, are less likely to feel that they are treated with contempt or belittled in the presence of their classmates. Killen (2010:37) also regards excellent teachers as effective communicators, describing them as people who maintain good relations with their learners, who give lucid explanations, who clearly articulate their expectations and who involve learners.

Feldman and McPhee (2010:379) also advocate the creation of a collaborative learning environment in the classroom, one in which learners will focus on collaborative learning. If teachers succeed in creating this kind of environment, the competitive environment in many classrooms becomes less so. They suggest that the traditional transmission model of teaching be replaced by learning environments influenced by constructivist learning principles, ones that value prior experiences and knowledge and welcome relevant challenges, questions and debates. This will not only support more effective learning, but also strong connections among students. Killen (2010:25) categorically states: "You should not expect learners to be engaged in meaningful learning if the environment is not supportive, encouraging and focused on learning."

\subsection{Refusing to conform/Create variation and variety}

Feldman and McPhee (2008:348) opine that we all have the capacity to do more than we think. We shall realise what we are capable of doing by mastering creative techniques. They advise teachers to encourage learners to take risks so their creative abilities can be nurtured and so thus feel more successful.

Due to the fact that learners experience knowledge in different ways - which also differ in respect of background knowledge, skills and talents - a one-size-fits-all approach will probably not be very successful (Killen, 2010:133-4). Killen also argues that we all get bored with doing the same thing for too long. This is especially true when we are inactive, such as when we are sitting quietly in a classroom. He advises that teachers should inter alia vary the following aspects of their direct instruction (Killen, 2010:134):

- The ways in which lessons commence (e.g. state the outcomes, ask a question, pose a problem and show an object that interests learners).

- The way in which learners' prior knowledge is gauged (e.g. pre-tests, brainstorming and surveys).

- The means by which learners gain access to information (e.g. lecture, hand-out, PowerPoint presentation, Internet, stories, television).

- The activities learners participate in (e.g. listening, reading, writing, speaking).

\subsection{Good planning}

Outstanding teachers come to class organised - ready to instruct (Feldman \& McPhee, 2008:130), because this not only demonstrates that they have mastered the subject content, but also their dedication and commitment to the instruction. Killen (2010:39) further holds that excellent teachers are well organised. They implement systems and processes to systematise all aspects of their teaching. This is ever so important because learners learn more effectively from well-organised teachers than from unorganised teachers (Killen, 1991 in Killen, 2010:39). Killen (2010:84) also warns teachers: 
You cannot expect individual lessons to be successful if they had not been planned thoroughly and integrated carefully into your medium and long-term plans.

\section{Conclusion}

As explained in paragraph 2, the first goal of our research was to provide evidence that, after attending and studying a live performance of a successful, popular performer like Neil Diamond, teachers and lecturers would be able to identify those attributes and strategies of the singer that might enable them to improve their classroom practices.

In our opinion, we have indeed provided evidence that educators can learn from Diamond specifically - and therefore likely from the arts in general - about improving their classroom practices. The learning team members often presented their observations and interpretations in poetic terms: "To be absolutely professional and to put on a perfect show, despite difficult, personal circumstances"; "I also enjoy my audience and our interaction. I enjoy what I get back" and, "Yes, we act, we become the performers." This is a clear indication that the learning team members were able to interpret, understand and learn about their teaching practices in artistic terms.

The AI team members also indicated that they learned from Diamond about, inter alia, the interaction between themselves and the learners in their classes ("I also enjoy my audience and our interaction. I enjoy what I receive"), that his passion inspires them ("Passion - for doing what I do to the best of my ability, and for transferring it to the children so they develop a love for my subject"), and that educators, too, have to prepare thoroughly ("Planning - doesn't it also take him some time to write a song? It's not something that is simply dashed off") - insights with which the educational fraternity are naturally familiar with.

What is however new is that the educators in this study were able to come to these insights while attending an enjoyable Neil Diamond concert and that they could learn from him about their classroom practices. Diamond's songs might indeed be pointing toward what the rest of the lives and careers of teachers might be like. We believe that, by embedding this learning process into the scientific knowledge presented in two acknowledged sources in the field of teaching practice, we have successfully achieved the second goal of our research, namely to validate the credibility of the knowledge obtained during this enjoyable learning experience.

We definitely do not want to argue that this method of teacher development should replace any of the existing methods. We readily admit that this was an exploratory study with only seven participants. The positive themes that we have identified from the responses were, however, embedded in current educational literature and the credibility and transferability thereof were established. What we do wish to contend, therefore, is that our research provides some convincing evidence that popular music does, indeed, provide an enjoyable and valid addition to the current range of available teacher training strategies.

\section{References}

Ary, D., Jacobs, L.C. \& Sorensen, C. 2010. Introduction to research in education. Wadsworth, Belmont.

TD, 9(3), Spec. ed, December 2013, pp. 493-504. 
Bloch, G. 2009. The toxic mix: what's wrong with South Africa's schools and how to fix it. Cape Town: Tafelberg.

Cooperrider, D.L., Whitney, D. \& Stavros, J.M. 2008. Appreciative inquiry handbook. 2nd ed. Brunswick, OH: Crown Custom Publishing, Inc. and San Francisco: Berrett-Koehler Publishers, Inc.

Diamond, N. 2008a. Neil Diamond: The Thank You Australia Concert. Live 1976. ArchAngel Television Productions. [DVD]

Diamond, N. 2008b. Neil Diamond: Hot August Night/NYC. Live from Madison Square Garden, August 2008. Sony Music. [DVD]

Feldman, J. \& McPhee, D. 2008. The science of learning $\mathcal{F}^{\circ}$ the art of teaching. New York: Thomson Delmar Learning.

Frith, S. 2001. Pop music. In Frith, S., Straw, W. \& Street, J. (Eds). The Cambridge companion to pop and rock. Cambridge: Cambridge University Press.

Killen, R. 2010. Teaching strategies for quality teaching and learning. Cape Town: Juta \& Co. Ltd.

Longhurst, B. 2007. Popular Music and Society (2 $2^{\text {nd }}$. Ed.). Cambridge, Polity Press.

Pretorius, J.P.H. 2009. Cliff Richard: An Educational Appreciation. Litnet Akademies, 6(3):155-184.

Pretorius, J.P.H., du Toit, D.S., Martin, C. and G. Daries. 2013. ABBA: An Educational Appreciation. Journal of Aesthetic Education, Vol. 47(1):72-103.

Soanes, C. \& Stevenson, A. 2005. Oxford Dictionary of English. Oxford, Oxford University Press.

Watkins, J.M., Mohr, B. \& Kelly, R. 2011. Appreciative Inquiry: Change at the speed of imagination. 2nd ed. San Francisco: Pfeiffer.

Whitney, D.K. \& Trosten-Bloom, A. 2010. The power of appreciative inquiry: a practical guide to positive change. San Francisco: Berret-Koehler Publishers, Inc. 